\title{
CONVERSION OF HYDROLYSATE TETANUS TOXIN TO TOXOID ${ }^{1}$
}

\author{
By EMANUEL B. SCHOENBACH, JULIUS J. JEZUKAWICZ, AND \\ J. HOWARD MUELLER \\ (From the Department of Bacteriology and Immunology, Harvard Medical School and School \\ of Public Health, Boston)
}

(Received for publication November 12, 1942)

In the case of diphtheria toxin obtained by the growth of a suitable strain on a medium free from peptone, some slight difficulty has been experienced in bringing about complete detoxification with formalin (1). This is probably due to the relatively high content of both toxin and amino acid nitrogen present, and has necessitated the use of formalin up to 0.5 per cent concentration and several weeks' incubation. Under these conditions, successful conversion to toxoid occurs, and the remaining toxoid is an adequate antigen (2).

A number of small scale experiments have been carried out in order to learn how tetanus toxins, produced on similar media, will conduct themselves. These have been uniformly encouraging, and indicate that toxin of this sort should find application in human immunization. Unlike diphtheria toxin, a relatively low concentration of formalin is adequate, and an incubation period of about three weeks suffices.

The following experiment is presented: $400 \mathrm{cc}$. of the toxin produced in the experiment quoted elsewhere (3) and which had been filtered through a small Berkefeld " $V$ " candle served for the experiment. Filtration was carried out March 18, 1941. The filtrate contained approximately 160 ,000 MLD per cc. for mice, and 50,000 for guinea pigs. Formalin in a quantity of $0.6 \mathrm{cc}$. $(=0.15$ per cent) was added and the material incubated at $37^{\circ} \mathrm{C}$. The treatment is tabulated below :

March 180.15 per cent formalin. Incubated $37^{\circ} \mathrm{C}$.

March 28 Cold room

$5.0 \mathrm{cc}$. in guinea pig-death in 5 days

April $237^{\circ} \mathrm{C}$.

April 4 Cold room

$5.0 \mathrm{cc}$. in guinea pig-death in 5 days

April $937^{\circ} \mathrm{C}$.

April 14 Cold room

$1.0 \mathrm{cc}$. in each of several guinea pigs-death

in 10 to 14 days

April $2537^{\circ} \mathrm{C}$.

1 Aided by a grant from the Commonwealth Fund.
April 260.05 per cent more formalin added

April 29 Cold room

$5.0 \mathrm{cc}$. in each of 2 guinea pigs-both survived with no symptoms

May $51.0 \mathrm{cc}$. in each of 12 pigs

June 1612 pigs all well. Each given 10 MLD of toxin (one of our own toxins identified as P-74 V). One unprotected control pig given 1.0 MLD of the same toxin died June 20 (101 hours).

June 26 Guinea pigs have shown no symptoms of tetanus during the 10-day interval. They were each bled a few cc. from the heart, the sera separated and pooled. Fifty per cent glycerol was added to the pooled sera and specimens sent to two manufacturers for an estimation of antitoxin content.

The report 2 from one was "considerably more than $1 / 10$ unit but not quite $1 / 2$ unit per cc." The second reported " 0.5 unit antitoxin per cc." Since the sample had been diluted with an equal volume of glycerol, the original pool must have contained approximately 1.0 unit antitoxin per cc.

A specimen of the toxoid was sent to the $\mathrm{Na}$ tional Institute of Health, Bethesda, Maryland, for further appraisal of its antigenicity. They reported that "protection was afforded against 10 and 20 MLD's of toxin, 6 weeks after immunization with $1 \mathrm{cc.}$."

It is clear that in this experiment the progress of detoxification was followed closely and the treatment accorded the toxin was directed by the toxicity to guinea pigs. As a result of several such experiments, it has become apparent that detoxification can be accomplished with considerable regularity in 3 weeks of incubation with 0.2 per cent formalin. The latter may be added all at one time, or in divided amounts, as in the experiment cited.

$2 \mathrm{We}$ are indebted to Dr. A. L. Joyner and Miss Frances Clapp of the Lederle Laboratories, Inc., and to Dr. Bettylee Hampil of Sharp and Dohme, Inc., for these determinations. 
SUMMARY

Tetanus toxin, prepared on a peptone-free hydrolysate medium, can be detoxified with 0.2 per cent formalin in about 3 weeks' time. The resulting toxoid is sufficiently antigenic to meet the requirements of the National Institute of Health for a fluid tetanus toxoid designed for human use. The use of toxoid of this type for immunization should prevent any possibility of anaphylactic reactions due to antigenic components of certain peptones, heretofore widely used in tetanus toxin production.
The work described in this paper was done under a contract, recommended by the Committee on Medical Research, between the Office of Scientific Research and Development and Harvard University.

\section{BIBLIOGRAPHY}

1. Pcrsonal communication-Dr. E. S. Robinson, Massachusetts State Antitoxin and Vaccine Laboratory.

2. Seal, S. C., and Johnson, S. J., Studies on the purification of alum-precipitated diphtheria toxoid. J. Infect. Dis., 1941, 69, 102.

3. Mueller, J. H., Schoenbach, E. B., Jezukawicz, J. J., and Miller, P. A., Production of tetanus toxin on peptone-free media. J. Clin. Invest., 1943, 22, 315. 